IZA DP No. 8323

Conspicuous Consumption in the United States and China

David Jinkins

July 2014 


\title{
Conspicuous Consumption in the United States and China
}

\author{
David Jinkins \\ Pennsylvania State University \\ and IZA
}
Discussion Paper No. 8323
July 2014

IZA
P.O. Box 7240
53072 Bonn
Germany

Phone: +49-228-3894-0

Fax: +49-228-3894-180

E-mail: iza@iza.org

Any opinions expressed here are those of the author(s) and not those of IZA. Research published in this series may include views on policy, but the institute itself takes no institutional policy positions. The IZA research network is committed to the IZA Guiding Principles of Research Integrity.

The Institute for the Study of Labor (IZA) in Bonn is a local and virtual international research center and a place of communication between science, politics and business. IZA is an independent nonprofit organization supported by Deutsche Post Foundation. The center is associated with the University of Bonn and offers a stimulating research environment through its international network, workshops and conferences, data service, project support, research visits and doctoral program. IZA engages in (i) original and internationally competitive research in all fields of labor economics, (ii) development of policy concepts, and (iii) dissemination of research results and concepts to the interested public.

IZA Discussion Papers often represent preliminary work and are circulated to encourage discussion. Citation of such a paper should account for its provisional character. A revised version may be available directly from the author. 


\section{ABSTRACT}

\section{Conspicuous Consumption in the United States and China*}

I develop a model of conspicuous consumption to empirically measure the importance of peer beliefs to Americans and Chinese. In the model, a consumer cares not only about the direct utility she receives from consumption, but also about the way her consumption pattern affects her peer group's belief about her well-being. I estimate the model on household budget surveys. According to model estimates, a Chinese consumer cares $20 \%$ more than an American consumer about peer beliefs. The absolute size of the conspicuous consumption motive in both countries is relatively small. I use the estimated model to evaluate the welfare effect of the 1990-2002 American luxury tax on automobiles. The luxury tax benefited nearly all Americans a small amount, but hurt the small fraction of consumers who love automobiles the most.

JEL Classification: D12

Keywords: conspicuous consumption, behavioral economics, applied microeconomics

Corresponding author:

David Jinkins

Pennsylvania State University

Department of Economics

Kern Building

State College, PA 16802

USA

E-mail: david.jinkins@gmail.com

\footnotetext{
* I wish to acknowledge the National Science Foundation EAPSI program for generous support of this project. I would also like to thank Jonathan Eaton, Ed Green, Jim Tybout, Venky Venkateswaran, Yaohui Zhao, and the participants in the Penn State $1 / O$ and Trade reading groups for helpful comments. Remaining errors are my own.
} 


\section{Introduction}

I wear a Seiko automatic watch. Over the course of a month, it picks up about five minutes. I knew it would do this before I bought it from reading online reviews, but even so I purchased it for about $\$ 100$ a few years ago. At the time, I could have picked up a much less expensive digital Casio from Wal-Mart which would have run more reliably, been easier to read, and been more water resistant. On just about any measure of watch performance the Casio would have outrun the Seiko, and yet there is the relatively expensive Seiko on my wrist.

When buying a car or a suit, a consumer considers how her social group will view the new purchase. This paper adds to the empirical literature on conspicuous consumption by developing and estimating a partial-equilibrium heterogeneous-agent structural model in which a consumer's peers infer his wealth after observing a subset of his purchases. Inference about welfare by his peer group causes a consumer to distort his consumption toward the purchase of visible goods.

This paper adds to the recent empirical literature on conspicuous consumption by developing and estimating a new structural model. To identify the strength of the motive to conspiciuously consume, previous literature has either relied on strong assumptions about the functional form of utility or arbitrary assumptions about the way in which observable consumption enters utility (Heffetz, 2011; Perez-Truglia, 2013). In the model developed below, households are allowed to have heterogenous, non-homethetic preferences. A peer group forms beliefs about the household's welfare based on the observable part of the household's consumption. The household cares about these peer group beliefs, and takes them into account when chosing how to allocate its income. In order to identify this more flexible model, I use differences in the perception of the visibility of good categories across demographic groups, along with differences in how these demographic groups spend their incomes. The estimation uses both a survey on the relative visibility of different categories of goods, and household-level consumption expenditure data. As it is used to calculate purchasing power, expenditure data is available for many countries and time periods.

I estimate the model separately using American and Chinese consumption expenditure data. The estimated model fits the data well. I find that the Chinese consumers care 20\% more than American consumers about peer group beliefs. Using the estimated model, I find that the 1990-2002 American luxury tax on automobiles had a small but positive welfare effect on all but around 2 in 10,000 American households. The households hurt by the 
tax were gearheads that derived a large amount of pleasure from automobile purchases.

In this paper as well as the literature I am following, a consumer considers peer group belief an end in itself. I put peer group belief about welfare directly into the utility function. Some might argue that people only care about peer group beliefs as the means to an ultimate consumptive endwearing a nice watch makes people trust you more, so you are more likely to get a loan or secure a business deal. I am sympathetic to this point of view, and this sort of signaling is doubtless going on to some degree. The two points of view about peer beliefs are complementary. From a long perspective, our brains might have been selected to care about peer group beliefs precisely because good standing makes successful reproduction more likely. In this case, the utils we get from positive peer group beliefs are an evolutionary rule of thumb.(Robson and Samuelson, 2010)

There are several strands of empirical literature that support the presence of a peer belief component in the utility function. Consider the ultimatum game in which one player proposes a split of a sum of money, and the other player decides whether to accept or reject. If the second player accepts, the money is allocated according to the split. If the second player rejects, neither player gets anything. There is a long and robust experimental literature showing that if people only care about immediate monetary payoffs, the splits they propose are too fair. Researchers have been careful to pair subjects who do not know each other and are unlikely to have interaction after the experiment, and the result still holds. One explanation is that there is some sort of social component in the utility function. (Fehr and Schmidt, 1999; Bolton and Ockenfels, 2000) A second defense comes from the literature on self-reported happiness and relative wealth. Luttmer (2004) finds that relative wealth compared with neighbors has a robust positive correlation with self-reported happiness, controlling for absolute wealth level. It seems hard to explain this fact without some sort of social component in the utility function. If, however, the reader is not convinced that there is a fundamental social belief component in the utility function, he may think of this paper as estimating a reduced form of a more complicated dynamic game.

This paper adds to the empirical literature on conspicuous consumption.(Bloch et al., 2004; Charles et al., 2009; Moav and Neeman, 2010, 2012) I extend work by Heffetz (2011), who conducts a telephone survey in the United States to determine the visibility of consumption goods. Heffetz analyzes household budget survey data, and finds evidence that the relatively visible goods identified by the survey are being used as a means to signal 
income. To my knowledge, the only other structural estimation of a utility function including conspicuous consumption is Perez-Truglia (2013). PerezTruglia follows earlier literature in using a two-good functional form, and a variety of specifications for how non-market goods like status enter utility. My specification below differs from Perez-Truglia's in a few important ways. Some cosmetic differences include that I allow for individual level preference heterogeneity and estimate a many good utility function. Any good can be used for signaling in my model, while in Perez-Truglia's model cars and clothes are the visible goods. More substantively, while PerezTruglia is focused on the provision of unobservable non-market goods (status), I assume that society cares only about an individual's unobservable welfare. This allows me to consider peer-group beliefs as an equilibrium outcome, rather than assume a functional form for the provision of a nonmarket good.

There is a relatively large and old related literature estimating what are known as interdependent preferences. Beginning with James Duesenberry's 1949 doctoral thesis,(Duesenberry, 1967) researchers have theorized that the consumption of neighbors affects own demand. A typical econometric model in this literature lets household demand parameters depend linearly on the average of the consumption of a reference group. A relationship between neighbor consumption and own consumption is taken to mean that preferences are interdependent. The literature, however, does not take a stand on why consumption neighborhood consumption should be linked in this particular way.

Structural estimation allows me to both measure the motive for conspicuous consumption across countries, and to calculate the welfare gains from an excise tax on a visible good category. A well-designed excise tax can raise nearly everyone's welfare. If income were directly observable by the peer group, there would be no reason to distort consumption towards visible goods and welfare would be higher than in the incomplete information world. One way to get people closer to the complete information allocation is to raise the price of the visible good, and then redistribute the proceeds of the tax. Loosely speaking, the rich are better off because they distort consumption less, and the poor are better off because they are getting a subsidy from the rich. If people care deeply about peer group belief, then the welfare gains from this sort of tax can be large. ${ }^{1}$

\footnotetext{
${ }^{1}$ Signaling distortions are particularly worrying when considering the economic lives of the poor. A recent study reports that in parts of India, the median household making under a dollar a day spends $10 \%$ of its income on festivals-this while $43 \%$ of such households did
} 


\section{An Empirical Model of Conspicuous Consump- tion}

There is a finite set of goods $G$. Each good has an exogenous price $p_{g}$. There is a continuum of consumers $I$. For each consumer, nature draws a income $w_{i}$, a preference type $\gamma_{i}$, and an observation type $t_{i} \in G$. A consumer allocate his income to goods in order to maximize his utility. Following previous literature on conspicuous consumption (Heffetz, 2011; Ireland, 1994), I assume a consumer's utility function consists of two additively separable parts.

$$
U\left(\mathbf{C}_{i}, \boldsymbol{\gamma}_{i}, t_{i}\right)=(1-\alpha) u\left(C_{i}, \boldsymbol{\gamma}_{i}\right)+\alpha u\left(C_{b}\left(c_{t_{i}}, \boldsymbol{\gamma}_{i}, t_{i}\right), \boldsymbol{\gamma}_{i}\right)
$$

The first term on the right-hand side of (1) is a fundamental utility $u$ : $\mathbb{R}_{+}^{I} \rightarrow \mathbb{R}$. Fundamental utility describes the pleasure a consumer gets directly from consuming a bundle of goods. The second term is the belief of a consumer's peer group over his utility. Peer group belief over the utility level of consumer $i$ is based on his expenditure on good category $t_{i}$. $C_{b}$ maps consumption of the observable good, observation type, and preference type to the unobservable full consumption vector. The preference type and observation type of consumer $i$ are known to his peer group. ${ }^{2}$

\subsection{Equilibrium Concept}

An equilibrium is a social belief function $C_{b}$ and a consumption function $C$ on $(W, \Gamma, G)$ such that:

1. For each consumer type $\left(w_{i}, \boldsymbol{\gamma}_{i}, t_{i}\right), C\left(w_{i}, \boldsymbol{\gamma}_{i}, t_{i}\right)$ solves the consumer's problem.

2. For each consumer types $\left(w_{i}, \boldsymbol{\gamma}_{i}, t_{i}\right), C\left(w_{i}, \boldsymbol{\gamma}_{i}, t_{i}\right)=C_{b}\left(C\left(w_{i}, \boldsymbol{\gamma}_{i}, t_{i}\right)_{t_{i}}, \boldsymbol{\gamma}_{i}, t_{i}\right)$.

The first condition says that a consumer chooses an optimum consumption bundle, and the second condition says that Consumer $i$ 's peer group learns his true type.

not have enough to eat throughout the year.(Banerjee and Duflo, 2007)

${ }^{2}$ The peer-group infers the one-dimensional income of a consumer from the onedimensional observed consumption choice of the observable good. If I allow for more than one observed good, then one-dimensional would be inferred from multi-dimensional consumption. As in a typical multi-dimensional screening model, the equilibrium will be driven by beliefs off the equilibrium path and there will be many possible equilibria. 


\subsection{Specializing to Cobb-Douglas}

Let the fundamental utility function be Cobb-Douglas:

$$
u(\mathbf{C}, \gamma)=\sum_{g=1}^{G} \gamma_{g} \ln \left(c_{g}\right)
$$

The model can then be written as a generalization of the Heffetz model to many goods and preference heterogeneity. ${ }^{3}$ In what follows I drop subscripts for Consumer $i$ to simplify notation. Let $t \in G$ be Consumer $i^{\prime}$ s observation type, and let $c_{t}^{*}$ be Consumer $i$ 's equilibrium consumption of the visible good. Equilibrium demand for good $g \neq t$ conditional on spending on the visible good is the standard Cobb-Douglas constant expenditure share:

$$
p_{g} c_{g}^{*}=\gamma_{g}\left(\sum_{j \neq t} \gamma_{j}\right)^{-1}\left(w-p_{t} c_{t}^{*}\right)
$$

Using the demands, we can write the utility function as a function of visible good consumption.

$U\left(c_{t}\right)=(1-\alpha)\left(\hat{\gamma} \ln \left(w-p_{t} c_{t}\right)+\gamma_{t} \ln \left(c_{t}\right)\right)+\alpha\left(\gamma_{t} \ln \left(s\left(c_{t}\right)\right)+\gamma_{t} \ln \left(c_{t}\right)\right)+\zeta(\mathbf{p}, \boldsymbol{\gamma})$

Here $\hat{\gamma}=\sum_{g \neq t} \gamma_{g}$ and $\zeta(\mathbf{p}, \gamma)$ is a constant which depends only on utility parameters and prices. The single-valued function $s\left(c_{t}\right)$ is the belief of the peer group about spending on non-visible goods $w-p_{t} c_{t}$.

Consumer $i$ maximizes utility function (3) subject to his budget constraint. The first order condition for an interior solution to his problem can be written:

$$
s^{\prime}\left(c_{t}^{*}\right)=\frac{1}{\alpha}\left((1-\alpha) p_{t}-\frac{\gamma_{t}}{\hat{\gamma}} \frac{s\left(c_{t}^{*}\right)}{c_{t}^{*}}\right)
$$

This differential equation has the solution:

$$
s\left(c_{t}^{*}\right)=\frac{\hat{\gamma}(1-\alpha)}{\gamma_{t}+\alpha \hat{\gamma}} p_{t} c_{t}^{*}+\frac{\hat{\gamma} \alpha}{\gamma_{t}+\alpha \hat{\gamma}} \frac{\mathrm{W}}{p_{t} \underline{\underline{\mathrm{C}}}}
$$

The constant in the solution (5) is pinned down because the lowest possible income type $\underline{W}>0$ has no reason to signal in a separating equilibrium. His

\footnotetext{
${ }^{3}$ In the Heffetz version, there are only two goods, one visible and the other invisible to society. In my version, there is one visible good for each observation type, and all the other goods are invisible.
} 
expenditure on the visible good $\underline{\underline{c}}$ is the fraction $\gamma_{t} / \sum_{j} \gamma_{j}$ of his income. As one might expect, the function $s$ is jointly homothetic in $c_{t}^{*}$ and $\mathrm{W}$.

Define equilibrium expenditure share on the visible good category $r=$ $p_{t} c_{t}^{*} / w$, the ratio $\gamma=\gamma_{t} / \hat{\gamma}$, and normalized income $\hat{w}=\underline{\mathrm{W}} / w$. Substituting in for the $s$ function and dividing by income, we have a simplified equilibrium condition:

$$
(1-r)\left(1+\frac{\gamma}{\alpha}\right)=\frac{(1-\alpha)}{\alpha} r+\left(r\left(1+\gamma^{-1}\right)\right)^{-\frac{\gamma}{\alpha}} \hat{w}^{1+\frac{\gamma}{\alpha}}
$$

\section{Description of Data and Sources}

This project requires two types of data. We need household-level consumer expenditure data, and we need information about how visible different good categories are relative to each other. Household expenditure data is widely available from national statistical agencies. Information on the visibility of different good categories is taken from a survey conducted in Heffetz (2011).

\subsection{Household Expenditures}

American household expenditure data is taken from the National Bureau of Economic Research.(National Bureau of Economic Research, 2011) This data set is publicly available, and features a large random sample of American household consumption decisions for selected years between 1981 and 2002. In addition to detailed information on household income and expenditures, the NBER data set contains demographic data on household members such as age, race, sex, and location. There are 47 good categories available in the NBER data set. Following Heffetz (2011) exactly, ${ }^{4}$ I aggregate into 29 expenditure categories. The cleaned NBER data set contains 160,617 household observations across 18 years.

Households display widely varying consumption behavior. Figure 1 is a scatter plot the 2001 log budget shares by log expenditures. Representative household models in the literature such as those by Heffetz and Ireland cannot replicate this heterogeneity. ${ }^{5}$ The heterogeneous preference model estimated in this paper can potentially match the noise observed in the data.

\footnotetext{
${ }^{4}$ Heffetz was kind enough to give me his STATA code.

${ }^{5}$ Heffetz (2011) contains a discussion of this issue.
} 


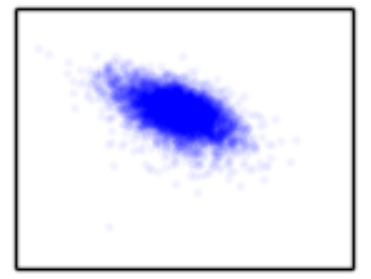

food at home

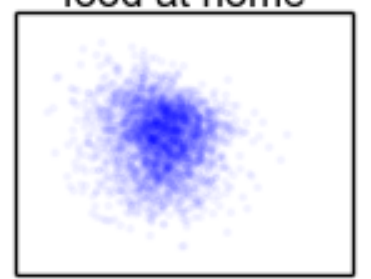

alcohol out

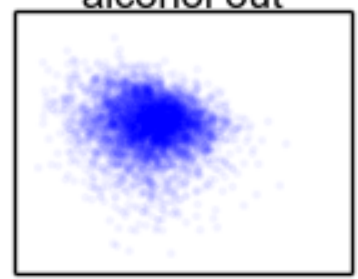

rent

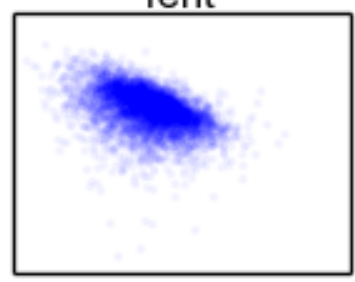

utilities

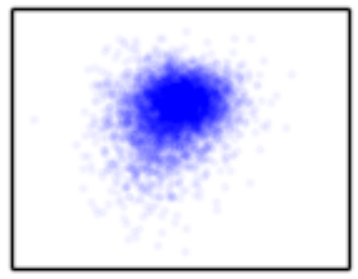

food out

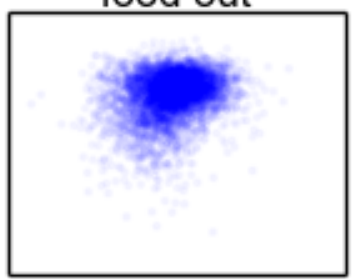

clothing

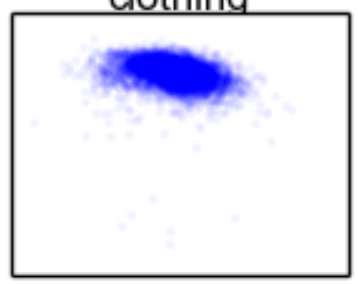

home

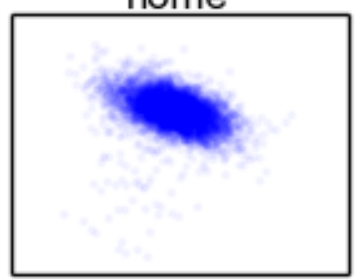

telephone

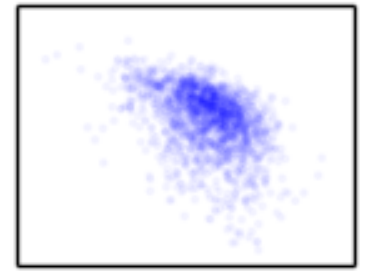

tobacco

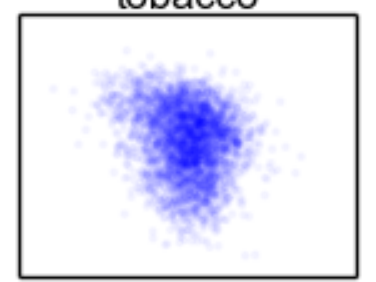

laundry

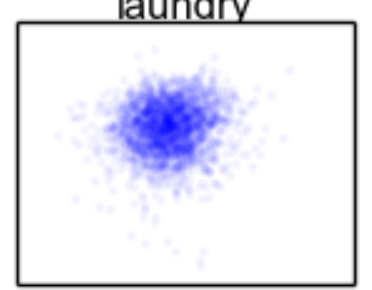

hotel

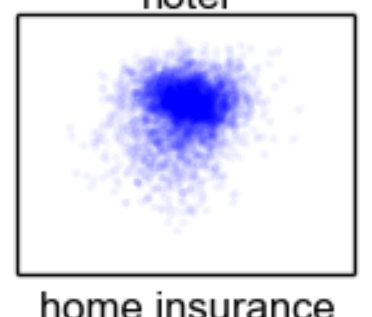

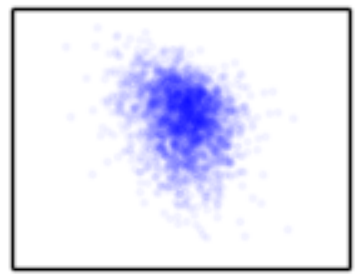

alcohol at home

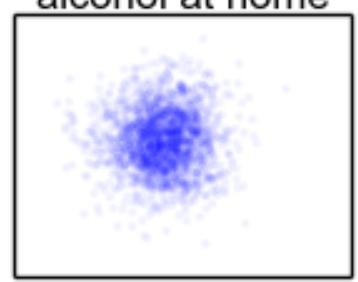

jewelry

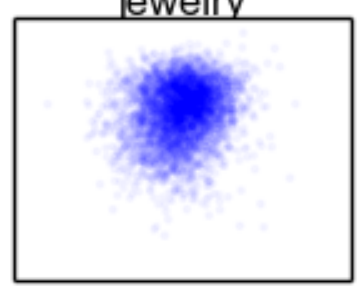

furniture

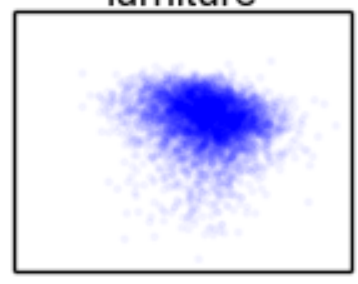

medical care

Figure 1: Log expenditure shares (y) by log expenditure (x) 


\begin{tabular}{llll}
\hline \hline US Cat & 1995 Chn Cat & 2002 Chn Cat & Chn Cat Name \\
\hline Fdh,Fdo & h27 & e1-e152-e153 & Food-Cig.-Alcohol \\
Alh,Alo & h30-h31 & e153 & Alcohol \\
Cig & h31 & e152 & Cigarettes \\
Bks & h37 & f631 & Textbooks \\
Edu & h38 to h42 & f63-f631 & Education-Textbooks \\
Bus,Car6 & h44 & f514 & Transportation \\
Utl & h45 to h46 & f72 & Water,Elec.,Fuel \\
Tel & h47 & f522 & Communication \\
Clo,Jwl & h32 & f2 & Clothes \\
Ot1,Ot2 & h33 & f6-f63 & Entertain. \\
Fur,Lry,Brb & h34,h36 & f3 & HomeEquip.,Facil., \\
Med,Lin & h48 & f4 & Health \\
Hom,Htl & h64 & f71 & Housing \\
Fee,Cha & h35 & f8 & Misc.Goods \\
\hline
\end{tabular}

Table 1: US-China Consumption Category Correspondence

For the Chinese household expenditures, I use publicly available data from the Chinese Household Income Project (CHIP). (Li, 2002) Like the American household expenditure data, the CHIP data is comprised of repeated cross-sections of Chinese households. In this study I use urban households surveyed in 1995 and 2002 for a total of 13,767 observations. I use 14 good categories which correspond to aggregates of those in the American household expenditure survey. Table 1 details the link between the American and Chinese expenditure data.

\subsection{Visibility Indexes}

Data concerning the visibility of good categories is taken from Heffetz (2011). Heffetz bases the index on randomized telephone surveys conducted in the United States in several waves around 2004. Survey respondents were asked how long it would take them to notice if a new acquaintance similar to themselves spent more than average on a particular good category. Respondents chose from five time periods ranging from almost immediately to almost never. Basic demographics similar to those in the consumer expenditure survey were also recorded for respondents.

From the survey responses, Heffetz creates indexes, called vindexes, between zero and one for each category of goods by averaging over survey results. A higher vindex value implies that a good category is more visible.

\footnotetext{
${ }^{6}$ Air, Gas, Cmn, Cin
} 
A result of this aggregation methodology is that the index is cardinal rather than ordinal. Two goods with similar index values are similar in visibility. Details on the implementation of the survey and calculation of the index are available in the original paper. Table 2 in the appendix presents vindex survey data.

As I do not have a vindex equivalent for China, I use the aggregated American vindex data for the Chinese estimation. Since there are fewer good categories in the Chinese data, I collapse the American vindex by taking the mean over aggregated good categories.

\section{Discussion of Identification Assumptions}

We are interested in $\alpha$, the weight given to the peer belief part of the utility function. The key identification issue is that, for a fixed $\alpha$, any consumption bundle can be rationalized by a particular set of utility function parameters $\gamma_{i}$. In order to separate preferences and conspicuous consumption, we need to take a stand on how utility parameters might be distributed. One natural assumption is that most people's preferences are broadly similar. To operationalize this idea, I assume that preferences for each household and each good category are independently drawn from lognormal distributions. In addition, to rationalize zero expenditure in a good category I assume that with some probability a consumer doesn't derive any pleasure from consumption of a particular category $\left(\gamma_{i g}=0\right)$.

A second challenge is that the Cobb-Douglass base utility assumption implies that there are no luxury or inferior goods. Absent any conspicuous consumption, expenditure shares are constant as household income increases. Figure 1 shows that expenditure shares are changing on average as household income increases. The combination of Cobb-Douglass utility and changing expenditure shares in principle identifies $\alpha$ in the model.

The Cobb-Douglass assumption is too strong, however. I want to allow a good like "food at home" to be inferior even without conspicuous consumption effects. To do this, I allow the location of the distribution of utility parameters to drift as a function of normalized income. In particular, the location parameter $\hat{\mu}_{g}\left(w_{i}\right)$ of the lognormal distribution for good category $g$ is given by (7).

$$
\hat{\mu}_{g}\left(w_{i}\right)=\psi_{g} \ln \left(\frac{w_{i}}{\underline{W}}\right)+\mu_{g}
$$

This 'money-in-the-utility-function' specification is somewhat ad hoc, 
but it allows us to keep the simple equilibrium condition (6) as well as allowing for rich evolution of expenditure shares with income. This distribution of utility parameters also breaks the simple identification of $\alpha$ from the correlation of household expenditure shares and income.

In order to regain identification, I use differences in observed vindexes across demographics. I assume that all utility parameters $\gamma_{i}$ are drawn out of the same distribution, but observation types $t_{i}$ are drawn with probability weighted by an individual's demographic specific vindex. The size of differences in average consumption between demographic groups are then informative about the weight $\alpha$ of peer group beliefs in the utility function.

In the United States I use visibility indexes for eight different demographic types of household. One dimension of differentiation is the age of the survey respondent (over/under age 40). The other dimension of differentiation is region in the United States (Northeast, Midwest, West, and South). The visibility probabilities are taken directly from Heffetz and normalized so that they sum to one. Table 3 in the appendix characterizes observation-type probability distributions for the demographic groups.

I have only a single Chinese demographic category, so when estimating Chinese preference parameters I cannot use an identification strategy based on differences across demographic groups. In the Chinese estimation, I take the $\psi_{g}$ 's in equation (7) as data from the American estimation. This assumption implies that luxury and inferior good categories are the same in both China and the United States. Deviations from Chinese expenditure share trends along with vindex probabilities identify $\alpha$.

\section{Estimation Procedure}

In order to estimate the parameter of interest $\alpha$, we must jointly estimate the observation type of each household and four preference distribution parameters for each good category. This is a large problem, so I split the estimation into two steps by using a 'hard' expectation maximization algorithm. In the first step (maximization), I condition on the observation type of each household and update $\alpha$ and preference distribution parameters. In the second stage, I take $\alpha$ and the preference distribution parameters as given and find the most likely observation type of each household (expectation). The algorithm stops when there is no change in $\alpha .^{7}$

\footnotetext{
${ }^{7}$ Intuitively this algorithm converges because in each step the likelihood must weakly increase. As with other expectation maximization algorithms, the algorithm used here will stop at either a local maximum, or a saddle point.
} 


\subsection{Maximization: Updating $\alpha$ and Preference Distribution Parameters}

\subsubsection{Overview}

In the maximization step, I condition the likelihood function on the observation type $t_{i}$ of each household and update $\alpha$ and lognormal preference distribution parameters $\mu_{g}, \sigma_{g}$, income-scaling parameter $\psi_{g}$, and a zero probability $z_{g}$. The outer structure of the maximization step uses a numerical optimizer to maximize the conditional likelihood over $\alpha$, and to treat the likelihood-maximizing preference parameters and preference distribution parameters as functions of $\alpha$. Given $\alpha$, the preference parameters $\gamma_{i}$ of each household can be calculated using observed consumption shares. Once we have preference parameters for each household, we can analytically calculate the most likely lognormal preference distribution and zero parameters.

\subsubsection{Recovering Household Preference Parameters Given $\alpha$}

Taking observation type $t_{i}$ and $\alpha$ as given, there is a mapping from observed consumption shares directly to household preference parameters. Consider a household of observed income type $w$, observed consumption vector $C$, and observation type $t$. Rearranging (2), $\gamma_{g}$ for $g \neq t$ are given by :

$$
\begin{aligned}
p_{g} c_{g} & =\frac{\gamma_{g}}{\sum_{g \neq t} \gamma_{g}}\left(w-p_{t} c_{t}\right) \\
\gamma_{g} & =\frac{p_{g} c_{g}}{\left(w-p_{t} c_{t}\right)}
\end{aligned}
$$

We can solve for the 28 non-observation type $\gamma_{g}$ 's up to a scaling factor $\sum_{g \neq t} \gamma_{g}=1$. Using (8) and the equilibrium condition (4) we can then solve for $\gamma_{t}$. Unfortunately, (4) is non-linear and in principle needs to be solved numerically for each household. To decrease estimation time, in practice I solve (4) on a 1000 point grid of visible consumption shares and incomes, and then linearly interpolate to find household specific $\gamma_{t}^{\prime}$ s.

\subsubsection{Updating Preference Distribution Parameters}

Given $\alpha$ and household preference parameters $\gamma_{i}$ for each household $i \in I$, the most likely zero probability $z_{g}^{*}$ for good category $g$ is the fraction of zero $\gamma_{i g}$ 's: 


$$
z_{g}^{*}=\frac{1}{\|I\|} \sum_{i} \mathbf{1}_{\gamma_{i g}=0}
$$

Let an upper bar denote sample means over non-zero $\gamma_{i}{ }^{\prime}$ s, and let $m_{i}$ refer to normalized income, $m_{i}=w_{i} / \underline{\mathrm{W}}$. The other likelihood-maximizing preference parameters are:

$$
\begin{aligned}
\psi_{g}^{*} & =\frac{\operatorname{cô}(\ln m, \ln \gamma)}{\operatorname{vâr}(\ln m)} \\
\mu_{g}^{*} & =\overline{\ln \gamma}-\psi_{g}^{*} \overline{\ln m} \\
\sigma_{g}^{2 *} & =\overline{\left(\ln \gamma-\psi_{g}^{*} \ln m-\mu_{g}^{*}\right)^{2}}
\end{aligned}
$$

\subsubsection{Full Conditional Likelihood Function}

I have shown how, given observation types, it is straight-forward to calculate preference parameters and likelihood maximizing preference distribution parameters as a function of $\alpha$. Let $\phi$ be the log-normal probability density function. The maximization step conditional log-likelihood function is given in (10). All preference parameters and preference distribution parameters are implicitly functions of $\alpha$.

$$
l^{1}(\alpha)=\sum_{i g}\left(\mathbf{1}_{\left\{\gamma_{i g}=0\right\}} \ln \left(z_{g}\right)+\mathbf{1}_{\left\{\gamma_{i g} \neq 0\right\}}\left(\ln \left(1-z_{g}\right)+\ln \phi\left(\gamma_{i g}, m_{i} \mid \mu_{g}, \sigma_{g}, \psi_{g}\right)\right)\right)
$$

Likelihood (10) is the objective function used by the numerical solver in the search for $\alpha$. This completes the characterization of the maximization step in the algorithm.

\subsection{Expectation: Updating Observation Type $t_{i}$}

Given the utility weight of social beliefs $\alpha$ and a set of preference distribution parameters, we find the most likely observation type for each household. Now preference parameters $\gamma_{i g}$ are a function of observation type $t$ and are calculated exactly as in Section 5.1.2. $\mathbf{v}_{i}$ is the household-specific vector of observation type probabilities. Household $i$ 's (unnormalized) probability of being observation type $t \in G$ is given by (11). 
$l_{i}^{2}(t)=\ln \left(v_{i t}\right)+\sum_{g}\left(\mathbf{1}_{\left\{\gamma_{i g}=0\right\}} \ln \left(z_{g}\right)+\mathbf{1}_{\left\{\gamma_{i g} \neq 0\right\}}\left(\ln \left(1-z_{g}\right)+\ln \phi\left(\gamma_{i g}, m_{i} \mid \mu_{g}, \sigma_{g}, \psi_{g}\right)\right)\right)$

For each household, I assign the observation type giving the highest probability. This concludes the discussion of the estimation routine.

\section{Results and an Application to an American Lux- ury Tax}

Chinese care about 20\% more than Americans about social beliefs. The weight of social beliefs $\alpha$ in American utility is 0.027 with standard error $1 \times 10^{-4}$. In Chinese utility, the weight of social beliefs is 0.033 with standard error 0.001 . Standard errors are bootstrapped by repeatedly redrawing from the data and reestimating the model. All estimated parameters are presented in Appendix ??.

The model is capable of simulating data similar to the real data set. Figure 2 is a scatter plot of simulated US data, superimposed on top of the scatter plots of the actual US data in figures 1 . The estimation also does well fitting observation types. The observation type distribution (for a particular demographic) should be the same as the vindex probability distribution. Figure 3 is a scatter plot of the vindex probabilities and the estimated observation type densities. Each point is labeled with the relevant good category, and the colors represent different demographic types (region and age). Although there is not a perfect correlation between vindex probabilities and observation type frequencies, there is a clear trend in the right direction. The model misses the most on good categories "car" and "jewelry". I suspect the problem is that these are durable goods, so that a single year of expenditure is a poor reflection of average expenditure in those categories.

\subsection{Policy Analysis: Luxury Tax}

In the model developed above, a consumer distorts his full-information utility-maximizing consumption bundle in order to signal his income. The signal is on expenditures, however, not on physical goods. In principle, a social planner could impose a sales tax on a highly visible good category in order to reduce physical consumption. In the real world, such a tax is 


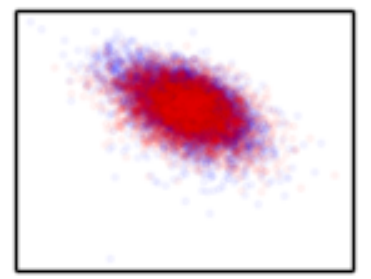

food at home

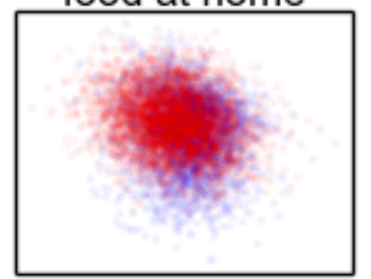

alcohol out

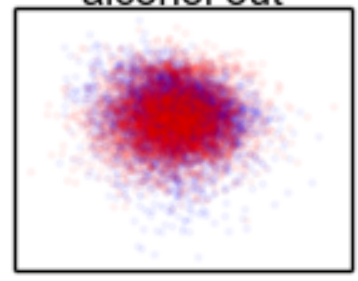

rent

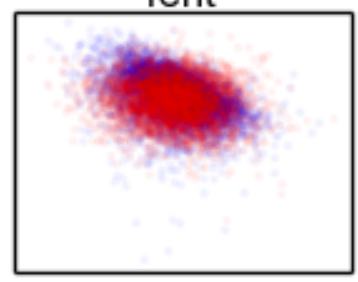

utilities

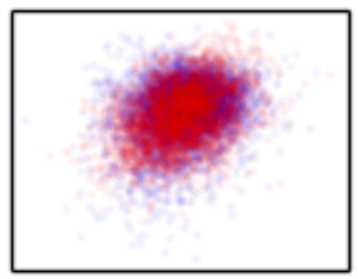

food out

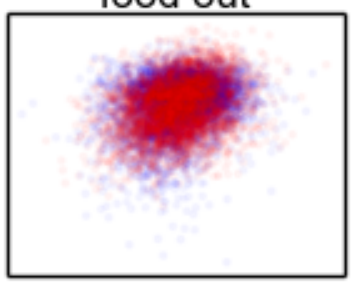

clothing

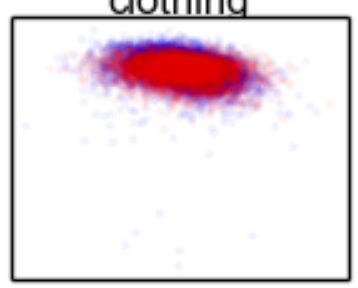

home

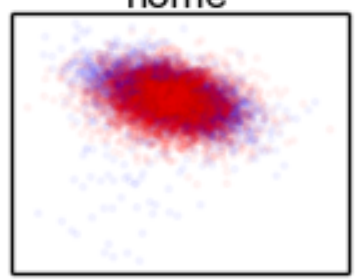

telephone

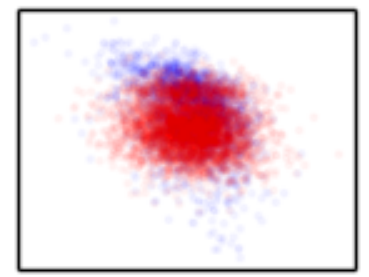

tobacco

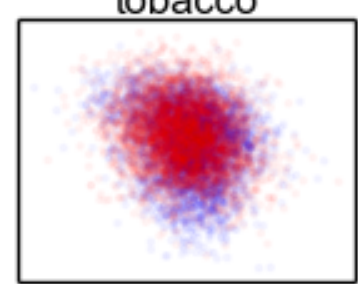

laundry

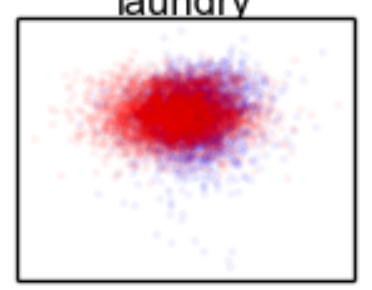

hotel

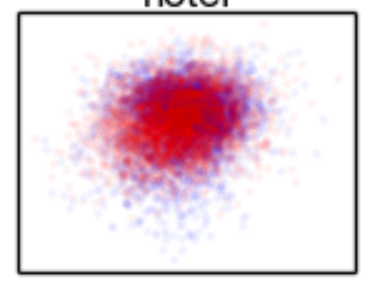

home insurance

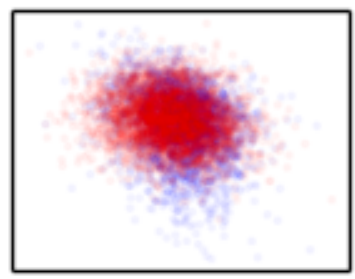

alcohol at home

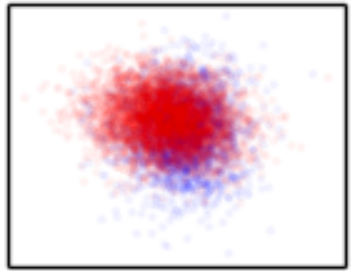

jewelry

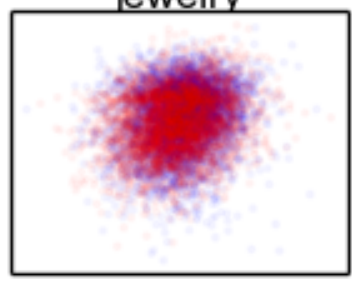

furniture

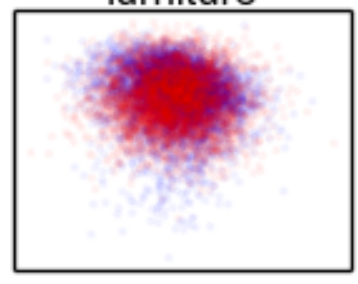

medical care

Figure 2: Log expenditure shares (y) by $\log$ expenditure $(\mathrm{x}), \operatorname{sim}=\mathrm{red}$, dat=blue 


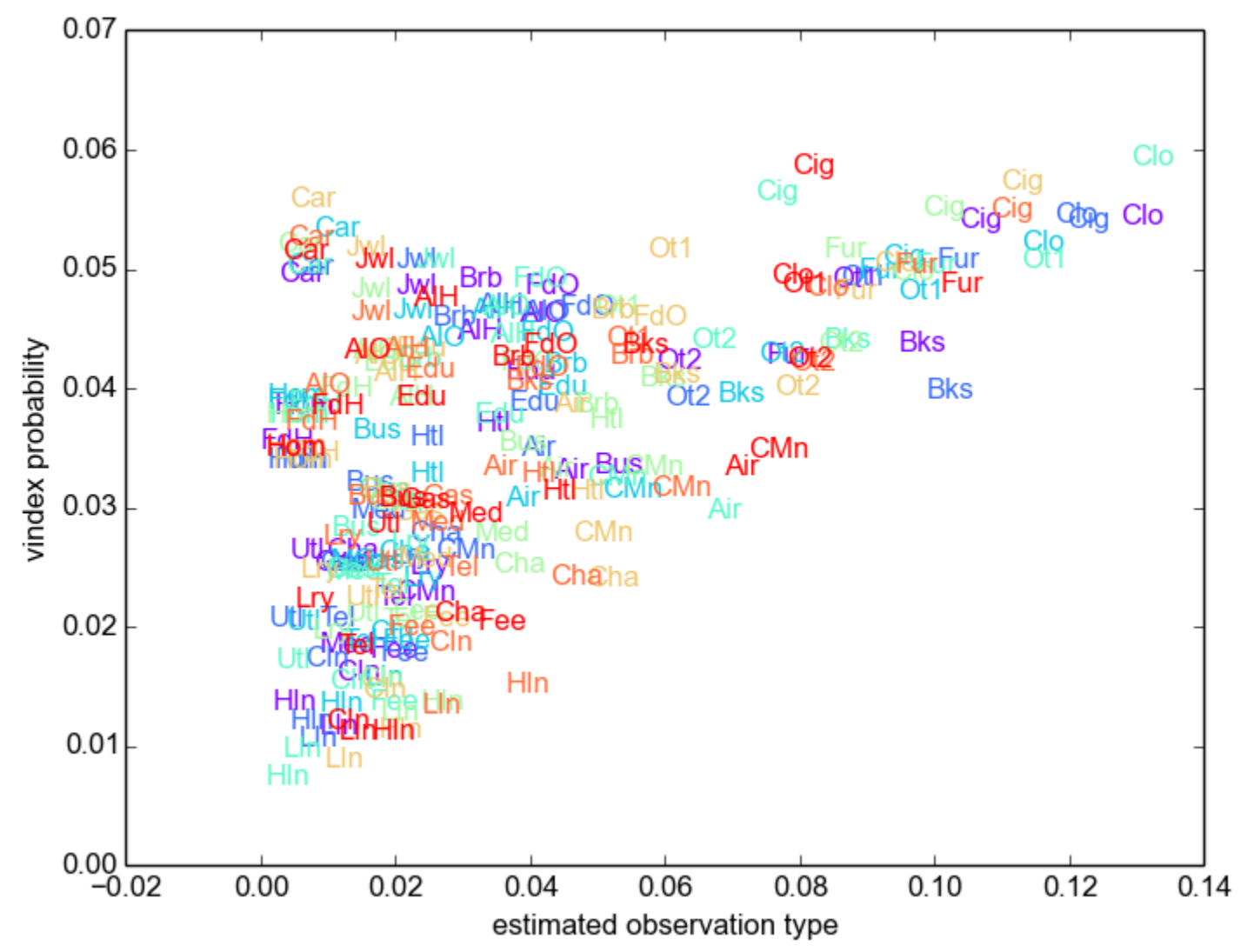

Figure 3: Estimated observation type frequencies vindex probabilities, by demographic 
known as a luxury tax. In this section I consider the welfare implications of one such tax scheme, an American luxury tax on automobiles.

\subsubsection{Application: Welfare Effect of US Automotive Luxury Taxes}

In 1990, President George H.W. Bush signed the Omnibus Budget Reconciliation Act into law. ${ }^{8}$ The OBRA contained a provision for a luxury tax on automobiles, as well as jewelry, furs, yachts, and personal aircraft. The tax on autos was $10 \%$ of the price exceeding $\$ 30,000$. As one might imagine, the luxury tax did not go over well at campaign fundraisers and was repealed in 1993 for all goods except automobiles. ${ }^{9}$ Congress finally scrapped the auto tax in 2002.

In this section, I measure the welfare effects of a $10 \%$ tax on automobiles, redistributed lump sum as a proportion of wealth. Redistributing the tax proportionally to wealth conveniently abstracts from the welfare effect of a transfer from the rich to the poor. In addition, taxes redistributed this way change neither the individual nor aggregate fraction of wealth optimally allocated to any particular good category, as relative wealth remains unchanged.

My luxury tax will be $10 \%$ of spending on automobiles. Let $\tau=0.1 / 1.1$ be the fraction of spending on autos taken by the government, let $s$ be the fraction by which the government increases wealth levels, let $l_{i}$ be the equilibrium fraction of auto expenditure in consumer $i$ 's total expenditures, and let $L$ be the aggregate fraction of spending on automobiles. Condition (??) balances the budget.

$$
\begin{aligned}
(1+s) \tau \sum_{i} w_{i} l_{i} & =s \sum_{i} w_{i} \\
s & =\frac{\tau L}{1-\tau L}
\end{aligned}
$$

Welfare change under the tax scheme is as in (13).

$$
\Delta u_{i}=\sum_{g \in G} \gamma_{i g} \ln (1+s)+\sum_{g \in l} \gamma_{i g} \ln (1-\tau)
$$

\footnotetext{
${ }^{8}$ Some readers might remember that this act proved television to be a poor medium for lip-reading.

${ }^{9} \mathrm{~A}$ cynical political realist might observe that luxury vehicles are often imported from Europe.
} 


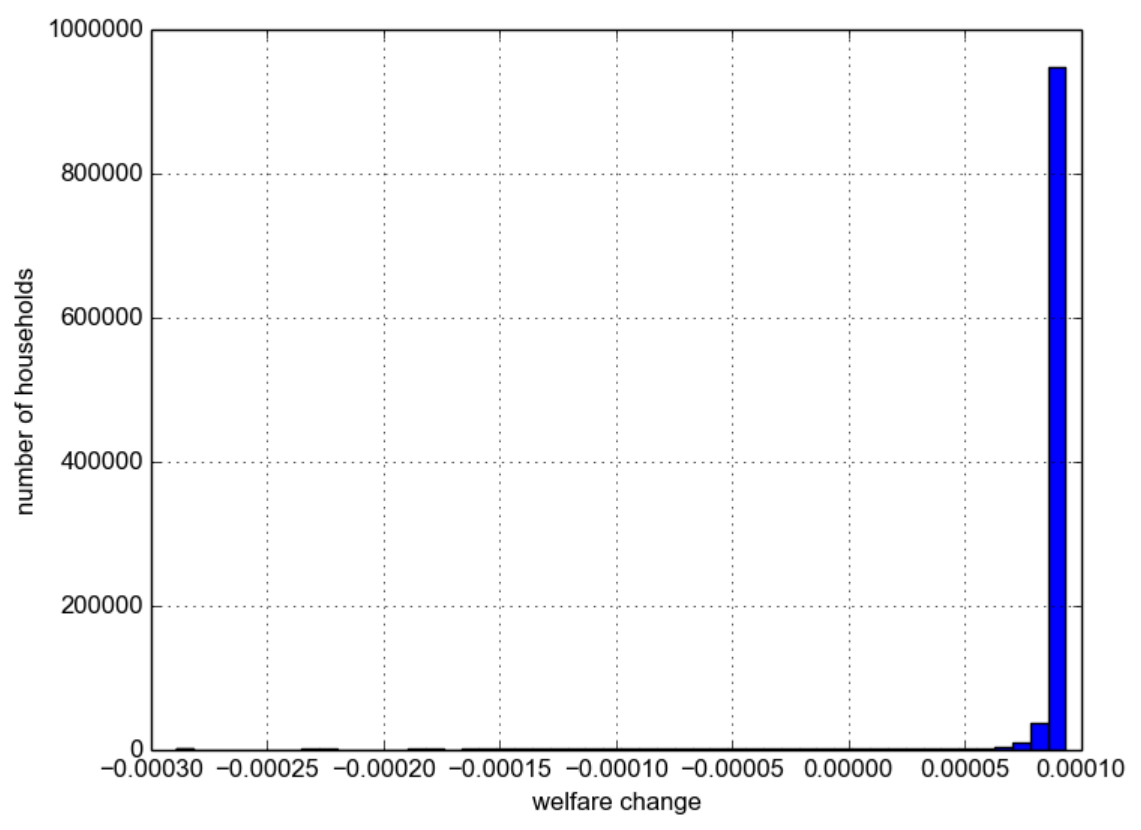

Figure 4: Histogram of welfare changes from a 10\% luxury auto tax

Using (??), it can be shown that $\ln (1+s)+\ln (1-\tau) \leq 0$ with the inequality strict when the aggregate share of spending on automobiles $L$ is less than one. Thus, it is impossible to have a truly Pareto tax scheme. That is, it is always possible that some unlucky consumer will draw all zero $\gamma_{i g}$ 's in non-luxury good categories, ensuring he will be harmed by a luxury tax. We can, however, potentially design taxes which benefit all but a very small fraction of consumers.

The relationship between $\alpha$ and the tax scheme here is through the share of expenditures households spend on automobiles, a relatively visible good category. Since many households have automobiles as an observation type, fixing preference parameters and the tax level $\tau$, the higher is $\alpha$ the higher will be government subsidies $s$ to consumers.

Figure 4 displays a histogram of welfare changes resulting from a $10 \%$ luxury tax, calculated for one million American households simulated using estimated model parameters from Section 6 . About $0.02 \%$, or two in 10,000 households are harmed by the auto luxury tax. The vast majority of households benefit from the automobile luxury tax. In contrast, a similar $10 \%$ sales tax on food at home harms $90 \%$ of households. 


\section{Summary}

I develop a structural conspicuous consumption model with preference heterogeneity estimable from widely available consumption expenditure data. In an application, I show how the estimated model can be used to measure the welfare implications of a tax on luxury goods.

The results of the estimation show that:

1. Peer group belief plays a small but non-zero role in overall consumption decisions. American and Chinese consumers value peer group belief under five percent as much as they value the direct utility from consumption.

2. Chinese consumers value peer group belief $20 \%$ more than American consumers.

3. Simple luxury taxes can lead to small welfare gains for nearly all households.

One strong assumption in the model is that a household's peer group sees only consumption expenditures on one good category. While a singledimensional signal generates the unique and simple equilibrium solution to the model, it is clearly counterfactual. In the real world, one's peer group sees a full, noisy vector of consumption expenditures. An earlier version of this paper had a model with this feature, but estimation involved numerically calculating a thirty dimensional integral for each consumer for each parameter trial. Future research might focus on relaxing this stark assumption about the observability of consumption. 


\section{References}

Banerjee, A. V. and Duflo, E. (2007). The Economic Lives of the Poor. The Journal of Economic Perspectives, 21(1):141-167.

Bloch, F., Rao, V., and Desai, S. (2004). Wedding Celebrations as Conspicuous Consumption. Journal of Human Resources, 39(3):675-695.

Bolton, G. and Ockenfels, A. (2000). ERC: A theory of equity, reciprocity, and competition. The American Economic Review, pages 166-193.

Charles, K. K., Hurst, E., and Roussanov, N. (2009). Conspicuous Consumption and Race. The Quarterly Journal of Economics, 124(2):425-467.

Duesenberry, J. S. (1967). Income, Saving, and the Theory of Consumer Behavior. Oxford University Press.

Fehr, E. and Schmidt, K. (1999). A Theory of Fairness, Competition, and Cooperation. The Quarterly Journal of Economics, 114(3):817-868.

Heffetz, O. (2011). A Test of Conspicuous Consumption: Visibility and Income Elasticities. The Review of Economics and Statistics.

Ireland, N. J. (1994). On Limiting the Market for Status Signals. Journal of Public Economics, 53:91-110.

Li, S. (2002). Chinese Household Income Project. Inter-university consortium for Political and Social Research.

Luttmer, E. (2004). Neighbors as Negatives: Relative Earnings and Wellbeing. Technical report, National Bureau of Economic Research.

Moav, O. and Neeman, Z. (2010). Status and Poverty. Journal of the European Economic Association, 8:413-420.

Moav, O. and Neeman, Z. (2012). Saving Rates and Poverty: The Role of Conspicuous Consumption and Human Capital. The Economic Journal, 122:933-956.

National Bureau of Economic Research (2011). Consumer Expenditure Survey Family-Level Extracts. http://www.nber.org/data/ces_cbo.html.

Perez-Truglia, R. (2013). Measuring the market value of non-market goods: The case of conspicuous consumption. Journal of Socio-Economics, 45:146154. 
Robson, A. and Samuelson, L. (2010). The Evoluationary Foundations of Preferences. Handbook of Social Economics, pages 221-310. 


\section{A Vindex Tables}

\begin{tabular}{lcc}
\hline \hline Category & Vindex & SE \\
\hline cigarettes & 0.76 & $(0.014)$ \\
cars & 0.72 & $(0.012)$ \\
clothing & 0.70 & $(0.013)$ \\
furniture & 0.68 & $(0.012)$ \\
jewelry & 0.67 & $(0.015)$ \\
recreation 1 & 0.66 & $(0.012)$ \\
food out & 0.61 & $(0.012)$ \\
alcohol home & 0.60 & $(0.014)$ \\
barbers etc & 0.60 & $(0.014)$ \\
alcohol out & 0.59 & $(0.014)$ \\
recreation 2 & 0.57 & $(0.013)$ \\
books etc & 0.57 & $(0.013)$ \\
education & 0.56 & $(0.014)$ \\
food home & 0.51 & $(0.014)$ \\
rent/home & 0.49 & $(0.016)$ \\
cell phone & 0.46 & $(0.016)$ \\
air travel & 0.46 & $(0.014)$ \\
hotels etc & 0.45 & $(0.013)$ \\
public trans & 0.44 & $(0.015)$ \\
car repair & 0.42 & $(0.014)$ \\
gasoline & 0.39 & $(0.016)$ \\
health care & 0.36 & $(0.014)$ \\
charities & 0.34 & $(0.014)$ \\
laundry & 0.33 & $(0.015)$ \\
home utilities & 0.31 & $(0.015)$ \\
home phone & 0.29 & $(0.015)$ \\
legal fees & 0.26 & $(0.013)$ \\
car insur & 0.22 & $(0.014)$ \\
home insur & 0.16 & $(0.012)$ \\
life insur & 0.16 & $(0.011)$ \\
underwear & 0.12 & $(0.011)$ \\
\hline
\end{tabular}

Table 2: Aggregate Vindex 


\begin{tabular}{lllllllll}
\hline \hline \multicolumn{3}{c}{ Interviewee age under 40} & \multicolumn{5}{c}{ Interviewee age over 40} \\
& NEast & South & MWest & West & NEast & South & Mwest & West \\
\hline Air & 3.2 & 3.0 & 3.4 & 2.9 & 3.2 & 3.2 & 3.7 & 3.2 \\
AlH & 4.4 & 4.5 & 4.6 & 4.3 & 3.8 & 4.2 & 4.0 & 4.6 \\
AlO & 4.5 & 4.3 & 4.5 & 4.6 & 4.2 & 3.9 & 4.2 & 4.2 \\
Bks & 4.3 & 3.8 & 3.9 & 4.3 & 4.0 & 3.9 & 4.0 & 4.2 \\
Brb & 4.8 & 4.1 & 4.5 & 4.1 & 3.8 & 4.2 & 4.5 & 4.1 \\
Bus & 3.2 & 3.5 & 3.1 & 2.7 & 3.4 & 3.0 & 3.0 & 3.0 \\
CIn & 1.5 & 1.8 & 1.6 & 1.4 & 1.4 & 1.7 & 1.4 & 1.1 \\
CMn & 2.2 & 3.0 & 2.5 & 3.1 & 3.2 & 3.0 & 2.7 & 3.4 \\
Car & 4.8 & 5.2 & 4.9 & 4.9 & 5.1 & 5.2 & 5.5 & 5.0 \\
Cha & 2.5 & 2.5 & 2.7 & 3.0 & 2.4 & 2.3 & 2.3 & 2.0 \\
Cig & 5.3 & 5.0 & 5.3 & 5.5 & 5.4 & 5.4 & 5.6 & 5.7 \\
Clo & 5.3 & 5.1 & 5.3 & 5.8 & 4.9 & 4.7 & 4.9 & 4.8 \\
Edu & 4.0 & 3.9 & 3.8 & 3.7 & 4.1 & 4.0 & 4.2 & 3.8 \\
FdH & 3.4 & 3.8 & 3.3 & 3.8 & 3.9 & 3.6 & 3.3 & 3.7 \\
FdO & 4.7 & 4.3 & 4.6 & 4.8 & 4.1 & 4.1 & 4.5 & 4.2 \\
Fee & 1.7 & 1.8 & 1.7 & 1.3 & 2.0 & 1.9 & 2.0 & 1.9 \\
Fur & 4.2 & 4.9 & 5.0 & 4.9 & 5.0 & 4.9 & 4.7 & 4.8 \\
Gas & 2.4 & 2.4 & 2.4 & 2.4 & 2.9 & 3.0 & 2.8 & 2.9 \\
HIn & 1.3 & 1.2 & 1.1 & 0.6 & 1.3 & 1.4 & 1.0 & 1.0 \\
Hom & 3.7 & 3.8 & 3.3 & 3.7 & 3.7 & 3.4 & 3.3 & 3.4 \\
Htl & 3.6 & 3.2 & 3.5 & 2.9 & 3.6 & 3.2 & 3.0 & 3.0 \\
Jwl & 4.7 & 4.5 & 5.0 & 5.0 & 4.7 & 4.5 & 5.1 & 5.0 \\
LIn & 1.0 & 1.5 & 1.0 & 0.9 & 1.2 & 1.2 & 0.8 & 1.0 \\
Lry & 2.4 & 2.3 & 2.5 & 2.6 & 1.9 & 2.6 & 2.4 & 2.1 \\
Med & 1.7 & 2.4 & 2.9 & 2.3 & 2.7 & 2.8 & 2.4 & 2.8 \\
Ot & 4.8 & 4.7 & 4.8 & 5.0 & 4.6 & 4.3 & 5.0 & 4.8 \\
Ot & 4.1 & 4.2 & 3.8 & 4.3 & 4.3 & 4.1 & 3.9 & 4.1 \\
Tel & 2.1 & 1.8 & 2.0 & 2.2 & 1.9 & 2.4 & 2.2 & 1.7 \\
Utl & 2.5 & 1.9 & 2.0 & 1.6 & 2.0 & 2.4 & 2.1 & 2.7 \\
\hline & & & & & & & & \\
\hline
\end{tabular}

Table 3: Observation type probabilities by demographic category 


\begin{tabular}{|c|c|c|c|c|c|c|c|c|}
\hline Good Cat & $\mu$ & std err & $\overline{c \sigma}$ & std err & $\psi$ & std err & $z$ & std err \\
\hline $\mathrm{FdH}$ & 3.98 & $(0.011)$ & 0.22 & $(0.002)$ & 0.44 & $(0.003)$ & 0.00 & $(0.000)$ \\
\hline $\mathrm{FdO}$ & -0.48 & $(0.025)$ & 0.82 & $(0.007)$ & -0.42 & $(0.006)$ & 0.06 & (0.001) \\
\hline Cig & 0.92 & $(0.020)$ & 0.38 & (0.003) & 0.22 & $(0.005)$ & 0.64 & $(0.001)$ \\
\hline $\mathrm{AlH}$ & 0.94 & $(0.016)$ & 0.68 & $(0.006)$ & 0.37 & (0.005) & 0.47 & $(0.002)$ \\
\hline $\mathrm{AlO}$ & 1.05 & $(0.026)$ & 1.19 & (0.007) & 0.48 & (0.008) & 0.46 & $(0.002)$ \\
\hline Clo & -0.81 & $(0.027)$ & 1.01 & $(0.011)$ & -0.42 & $(0.006)$ & 0.05 & $(0.000)$ \\
\hline Lry & 0.79 & (0.031) & 1.24 & (0.010) & 0.47 & $(0.009)$ & 0.31 & $(0.002)$ \\
\hline Jwl & 0.61 & $(0.021)$ & 0.90 & (0.008) & 0.32 & $(0.006)$ & 0.57 & $(0.002)$ \\
\hline $\mathrm{Brb}$ & 0.07 & $(0.020)$ & 0.64 & $(0.006)$ & 0.11 & $(0.005)$ & 0.09 & $(0.001)$ \\
\hline Hom & 4.17 & (0.011) & 0.19 & $(0.001)$ & 0.23 & $(0.003)$ & 0.00 & $(0.000)$ \\
\hline $\mathrm{Htl}$ & 0.09 & (0.019) & 0.60 & $(0.010)$ & 0.06 & $(0.006)$ & 0.52 & $(0.002)$ \\
\hline Fur & -0.87 & $(0.032)$ & 1.45 & $(0.015)$ & -0.29 & (0.009) & 0.17 & (0.001) \\
\hline Utl & 2.50 & $(0.020)$ & 0.31 & $(0.002)$ & 0.27 & $(0.005)$ & 0.04 & $(0.001)$ \\
\hline Tel & 2.12 & $(0.024)$ & 0.45 & $(0.006)$ & 0.37 & $(0.006)$ & 0.01 & $(0.000)$ \\
\hline HIn & -0.61 & $(0.032)$ & 1.18 & (0.008) & -0.22 & $(0.008)$ & 0.19 & $(0.001)$ \\
\hline Med & 2.03 & $(0.030)$ & 1.35 & $(0.014)$ & 0.16 & $(0.008)$ & 0.05 & $(0.001)$ \\
\hline Fee & 0.13 & (0.027) & 1.25 & $(0.012)$ & 0.15 & $(0.007)$ & 0.25 & $(0.002)$ \\
\hline LIn & 0.38 & $(0.023)$ & 0.73 & (0.006) & 0.06 & $(0.006)$ & 0.45 & $(0.001)$ \\
\hline Car & -2.31 & $(0.028)$ & 1.06 & (0.008) & -0.86 & $(0.008)$ & 0.76 & (0.001) \\
\hline CMn & -0.45 & $(0.023)$ & 1.40 & $(0.012)$ & -0.23 & $(0.006)$ & 0.13 & $(0.001)$ \\
\hline Gas & 0.92 & $(0.024)$ & 0.53 & (0.005) & -0.04 & $(0.006)$ & 0.07 & $(0.001)$ \\
\hline CIn & 0.62 & (0.018) & 0.44 & (0.005) & -0.02 & $(0.005)$ & 0.22 & $(0.001)$ \\
\hline Bus & 0.78 & $(0.025)$ & 0.99 & (0.008) & 0.33 & $(0.008)$ & 0.63 & $(0.001)$ \\
\hline Air & 0.02 & $(0.014)$ & 0.41 & (0.008) & 0.00 & $(0.004)$ & 0.67 & $(0.002)$ \\
\hline Bks & -0.75 & $(0.026)$ & 0.89 & (0.008) & -0.16 & $(0.007)$ & 0.07 & $(0.000)$ \\
\hline Ot1 & -0.27 & (0.027) & 1.36 & $(0.012)$ & -0.04 & (0.007) & 0.29 & $(0.001)$ \\
\hline Ot2 & -0.72 & $(0.034)$ & 0.89 & $(0.009)$ & -0.40 & (0.009) & 0.07 & $(0.001)$ \\
\hline Edu & -0.21 & (0.017) & 0.86 & (0.009) & -0.06 & $(0.005)$ & 0.70 & $(0.002)$ \\
\hline Cha & -0.06 & (0.031) & 1.35 & (0.011) & -0.04 & (0.009) & 0.41 & $(0.001)$ \\
\hline$\omega$ & 0.027 & $(0.000)$ & & & & & & \\
\hline
\end{tabular}

Table 4: US Parameter Estimates 


\begin{tabular}{lcccccccc}
\hline \hline Good Cat & $\mu$ & std err & $\sigma$ & std err & $\psi$ & std err & z & std err \\
\hline Fdh/Fdo & 3.79 & $(0.111)$ & 0.13 & $(0.889)$ & 0.01 & $(0.007)$ & 0.00 & $(0.007)$ \\
Alh/Alo & 0.70 & $(0.111)$ & 1.08 & $(0.889)$ & 0.22 & $(0.007)$ & 0.47 & $(0.007)$ \\
Cig & 0.08 & $(0.077)$ & 3.72 & $(0.571)$ & 0.42 & $(0.004)$ & 0.10 & $(0.004)$ \\
Bks & 2.02 & $(0.013)$ & 0.72 & $(0.017)$ & -0.04 & $(0.001)$ & 0.01 & $(0.001)$ \\
Edu & 0.54 & $(0.022)$ & 1.34 & $(0.050)$ & -0.22 & $(0.002)$ & 0.03 & $(0.002)$ \\
Bus/Car & 1.38 & $(0.020)$ & 1.62 & $(0.040)$ & 0.09 & $(0.002)$ & 0.03 & $(0.002)$ \\
Utl & 1.02 & $(0.071)$ & 2.06 & $(0.488)$ & 0.11 & $(0.003)$ & 0.07 & $(0.003)$ \\
Tel & -0.50 & $(0.022)$ & 1.44 & $(0.046)$ & -0.13 & $(0.005)$ & 0.17 & $(0.005)$ \\
Clo/Jw1 & 1.27 & $(0.117)$ & 1.79 & $(1.142)$ & 0.37 & $(0.006)$ & 0.30 & $(0.006)$ \\
Ot1/Ot2 & 0.98 & $(0.021)$ & 1.32 & $(0.038)$ & -0.06 & $(0.006)$ & 0.25 & $(0.006)$ \\
Fur/Lry/Bks & -0.72 & $(0.035)$ & 0.79 & $(0.085)$ & -0.16 & $(0.007)$ & 0.55 & $(0.007)$ \\
Med/Lin & -0.08 & $(0.062)$ & 1.87 & $(0.267)$ & 0.15 & $(0.007)$ & 0.51 & $(0.007)$ \\
Hom/Htl & 2.10 & $(0.011)$ & 0.59 & $(0.012)$ & 0.27 & $(0.001)$ & 0.01 & $(0.001)$ \\
Fee/Cha & 1.61 & $(0.018)$ & 1.41 & $(0.032)$ & 0.05 & $(0.001)$ & 0.01 & $(0.001)$ \\
\hline$\alpha$ & 0.2618 & $(0.000)$ & & & & & & \\
\hline
\end{tabular}

Table 5: Chinese Parameter Estimates 